\title{
Taste-sickness associations in young rats over varying delays, stimulus, and test conditions
}

\author{
GERARD M. MARTIN and W. K. TIMMINS \\ Australian National University, Canberra, A.C.T., Australia
}

\begin{abstract}
We showed, as had previous investigators, that young rats formed taste-sickness associations that were weaker than those of mature rats; associations were not formed over a delay greater than $45 \mathrm{~min}$, and aversions did not survive a 60 -min test session. The difficulty young rats had withholding consumption and their poor sensitivity to taste and sickness contributed to the weak aversions. Choice tests revealed aversions that had apparently extinguished during a no-choice test, and animals that were allowed to mature prior to the first test readily withheld consumption for $60 \mathrm{~min}$. Furthermore, young rats formed an aversion over a delay of $2.5 \mathrm{~h}$ when the concentrations of saccharin and lithium chloride were increased. Aversions to the stronger saccharin did not extinguish over two one-bottle tests and were retained for 52 days.
\end{abstract}

The differences between experiments that have successfully demonstrated good learned aversions in young animals and those that have not are extensive. Typically, two age groups are examined. Age of the young group at the time of training has varied from 12 days (Gregg, Kittrell, Domjan, \& Amsel, 1978) to 29 days (Baker, Baker, \& Kesner, 1977). Furthermore, the flavoring and sickness-inducing agents used, the duration of exposure to the taste, the mode of presenting the taste at training and test, and the interval between training and test vary quite dramatically between experiments. These differences have resulted in the contrasting claims that animals of 23 and 29 days of age form taste aversions with difficulty (Baker et al., 1977; Klein, Domato, Hallstead, Stephens, \& Mikulka, 1975) and that 15-day-old rats form taste aversions over a delay of $2 \mathrm{~h}$ (Gregg et al., 1978).

\section{EXPERIMENT 1}

In Experiment 1, we determined an age at which the ability of young rats to learn flavor aversions seemed impaired under our laboratory conditions. In later experiments, we examined various factors that might be responsible for the impairment.

\section{Method}

Subjects. Ninety-eight female Wistar hooded rats from the

The authors thank the Department of Psychology at the Australian National University for financial support throughout this experiment. We thank Anne Wells for technical assistance and $W$. P. Bellingham for discussion at the time of experimentation. We also thank S. H. Revusky for his comments on the earlier drafts of this manuscript, Gerard M. Martin's present address is: Department of Psychology, Memorial University, St. John's, Newfoundland, Canada A1B 3X9. W. K. Timmins' present address is: D.D.I.A.E., School of Arts, Darling Heights, Toowoomba, Queensland, Australia 4350.
Psychology Department's breeding colony at Australian National University were assigned to various age and experimental conditions as litters became available.

Procedure. Rats, which were $18,28,38$, or 48 days of age, were moved to individual wire cages that were $21 \times 21 \times 20 \mathrm{~cm}$ high; food and tap water were provided ad lib. A restricted drinking schedule was introduced on the following day; animals were allowed $10 \mathrm{~min}$ access to tap water at $1000 \mathrm{~h}$ and $3 \mathrm{~h}$ access from 1200 to $1500 \mathrm{~h}$. The experimental groups had .1\% saccharin solution substituted for tap water during the 10 -min drinking session at $1000 \mathrm{~h}(\mathrm{n}=11,8,8$, and 8 for the 23-, 33-, 43-, and 53-day-old groups, respectively). They were injected intraperitoneally (ip) with $.3 \mathrm{M} \mathrm{LiCl}(1.27 \mathrm{~g} / 100 \mathrm{ml}$ of distilled water), at a dosage of $1 \mathrm{ml} / 100 \mathrm{~g}$ body weight, immediately after the bottle was removed. Animals in the saline control group also had saccharin substituted for tap water, but were injected with an equivalent volume of physiological saline $(n=9,8,8$, and 8 for the 23-, 33-, 43-, and 53-day-old groups, respectively). Animals in the $\mathrm{LiCl}$ control group received tap water as usual and were injected with an equivalent volume of $\mathrm{LiCl}(\mathrm{n}=7,8,7$, and 8 for the 23-, 33-, 43-, and 53-day-old groups, respectively).

All animals were given access to a saccharin solution for $1 \mathrm{~h}$ 3 days later at $1000 \mathrm{~h}$. Consumption was measured after $10 \mathrm{~min}$ and again after $60 \mathrm{~min}$.

\section{Results and Discussion}

One-way analyses of variance showed that there were no differences between groups of the same age on the training day (Fs $<1$ ).

Figure 1 shows the mean amount of saccharin consumed over the 10- and 60-min tests. All age groups differed reliably over the 10 -min test: 23 days $[F(2,24)=11.79, \mathrm{p}<.01], 33$ days $[\mathrm{F}(2,21)=4.92$, $\mathrm{p}<.05], 43$ days $[\mathrm{F}(2,20)=6.85, \mathrm{p}<.05]$, and 53 days $[F(2,21)=3.33, p<.01]$. Scheffé multiple comparisons showed that the group that had saccharin consumption paired with $\mathrm{LiCl}$ on the training day consumed reliably less saccharin than the control groups (all ps $<.05$ ). All groups, with the exception of the 23-day-old group $[\mathrm{F}(2,24)=.80, \mathrm{p}>.05]$, also differed reliably (ps $<.05$ ) over the 60 -min test.

Our 23-day-old rats, like those of Baker et al. 


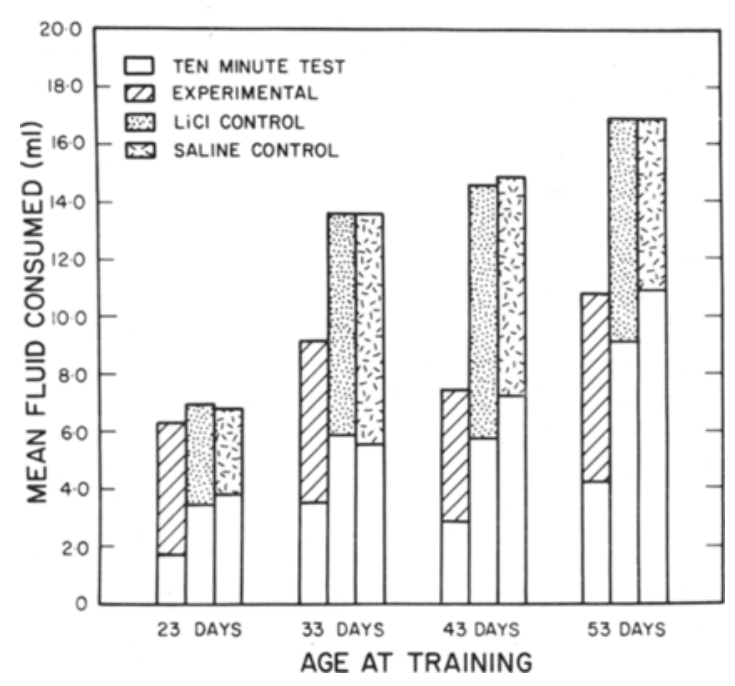

Figure 1. Mean amount of saccharin consumed over 60 min on the test day by the groups in Experiment 1. The lower white portion represents the fluid consumption over the first $10 \mathrm{~min}$.

(1977), maintained an aversion over a short test session. Our findings, however, are not consistent with those of Klein et al. (1975), who failed to demonstrate an aversion in young rats when a short test session was used. Klein et al. (1975) maintained their animals on $85 \%$ of their preexperiment fluid consumption. Other investigators, like us, maintained their animals on a limited access schedule. Hence, the need for fluid repletion by the young rats in Klein's experiment may have masked the aversion.

\section{EXPERIMENT 2}

The following two experiments determined whether the nature of the test and the age of the animals at the time of test contributed to the disappearance of an aversion over $60 \mathrm{~min}$ in 26-day-old rats. In Experiment $2 \mathrm{~A}$, our earlier findings on 26-day-old rats were replicated. In addition, the young rats were given a choice between saccharin and tap water on the day after the apparent extinction of the taste aversion. The presence of a saccharin aversion during the more sensitive retest would indicate that the young rat's difficulty withholding consumption contributed to the disappearance of an aversion during the first test. In Experiment 2B, the rats were trained when 23 days old and were tested when 33 days old. The maintenance of a saccharin aversion in 33-dayold rats over $60 \mathrm{~min}$, in contrast with its disappearance in 26-day-old rats, would also indicate that the young rats' difficulty withholding consumption contributed to the apparent extinction of the saccharin aversion.

\section{Method}

Experiment 2A. The materials used and procedure followed were the same as those employed in Experiment 1. Eighteen animals, which were 23 days old, were given .1\% saccharin instead of tap water during the 1000 -h drinking session. Half these animals were injected with $\mathrm{LiCl}$ and the other half were injected with an equal volume of physiological saline. The $\mathrm{LiCl}$ control group $(n=8)$ was given tap water during the $1,000-h$ drinking session. This group was injected with $\mathrm{LiCl}$ after the tap water was removed.

A $.1 \%$ saccharin solution was substituted for tap water for $60 \mathrm{~min}$ during the 1000-h drinking session when the rats were 26 days old. On the following day, all rats were given a choice for $60 \mathrm{~min}$ between tap water and $.1 \%$ saccharin during the 1,000-h drinking session.

Experiment 2B. This experiment was the same as Experiment 1 up to and including when the rats were 23 days of age. There were eight rats each in the experimental, the $\mathrm{LiCl}$, and the saline control groups. The rats were allowed ad lib access to food and water from 24 to 29 days of age. The deprivation procedure was then reinstated. A .1\% saccharin solution was substituted for tap water during the 1,000 -h drinking session when the rats were 33 days of age.

\section{Results and Discussion}

Experiment 2A. The findings from the first test day replicated those observed in Experiment 1. A reliable difference was obtained on the first test day over the 10 -min test $[F(2,23)=5.49, p<.05]$. Scheffé multiple comparisons showed that the experimental (mean $=2.7 \mathrm{ml}$ ) group drank less than the saline $($ mean $=3.9 \mathrm{ml})$ and $\mathrm{LiCl}($ mean $=4.1 \mathrm{ml})$ control groups ( $p s<.05$ ). A reliable difference between groups was not obtained when the analysis was carried out on the 60 -min saccharin consumption $(\mathrm{F}<1)$. The retest data were converted to suppression ratios (retest saccharin consumption/retest saccharin + retest tap water consumption). The groups differed reliably over the 10 -min retest session $[\mathrm{F}(2,23)=$ $13.35, \mathrm{p}<.01]$ and over the whole of the 60 -min session $[F(2,23)=7.87, p<.01]$. Scheffé multiple comparisons showed that the experimental group had a lower saccharin preference than both control groups over both the 10 -min (mean $=.42$ for the experimental vs. mean $=.72$ and mean $=.69$ for the $\mathrm{LiCl}$ and saline control groups, respectively) and the 60 -min (mean $=.45$ for the experimental vs. mean $=.71$ and mean $=.68$ for the $\mathrm{LiCl}$ and saline control groups, respectively) tests (all ps $<.05$ ). Apparently, the more sensitive choice test is required to demonstrate an aversion in young rats when the test session is $60 \mathrm{~min}$ in duration.

Experiment 2B. The rats retained the saccharin aversion over 10 days, and the aversion did not extinguish during the 60 -min test session. There were reliable differences between the groups over both the $10-\min [F(2,21)=25.30, \mathrm{p}<.01]$ and $60-\mathrm{min}$ sessions $[F(2,21)=15.69, p<.01]$. Scheffé multiple comparisons showed that the experimental group drank reliably less saccharin (means $=2.1$ and $7.5 \mathrm{ml}$ for 10 and $60 \mathrm{~min}$, respectively) than either the saline (means $=5.8$ and $10.9 \mathrm{ml}$ for 10 and $60 \mathrm{~min}$, respectively) or the $\mathrm{LiCl}$ (means $=7.5$ and $14.0 \mathrm{ml}$ for 10 and $60 \mathrm{~min}$, respectively) control group (all ps $<.05$ ). 


\section{EXPERIMENT 3}

Twenty-three-day-old rats showed a strong aversion to $.1 \%$ saccharin when a choice test was employed. The following experiment assessed further the ability of young rats to form taste-sickness associations under our stimulus conditions. We varied the delay between the saccharin and the injection of the $\mathrm{LiCl}$ and measured the aversion formed by the young rats. Formation of a tastesickness association over a long delay would indicate that the aversions formed by young rats were comparable to those observed in adults when the difficulty young rats have withholding consumption was taken into account. Failure to form taste-sickness associations over long delays would indicate that other factors also contribute to the weak aversions observed in young rats.

\section{Method}

Water was provided from two bottles throughout the experiment and the procedure was the same as in Experiment 1. Forty-eight rats were given a solution of .1\% saccharin instead of tap water when they were 23 days old. They were injected with $\mathrm{LiCl} 0$ $(n=7), 15(n=8), 30(n=8), 45(n=8), 60(n=9)$, or $120 \min (n=8)$ after the saccharin was removed. Seven $\mathrm{LiCl}$ control rats drank tap water when 23 days old and were injected with an equivalent volume of $\mathrm{LiCl}$ immediately after the fluid was removed.

Three days later, all rats were given a choice between tap water and saccharin for $60 \mathrm{~min}$.

\section{Results}

Preference ratios from the test day are presented in Figure 2. An analysis of variance showed that the groups differed reliably over the 10 -min test session $[F(6,48)=2.30, p<.05]$. Scheffé multiple comparisons showed that the group that was poisoned immediately and 15 min after saccharin removal had lower saccharin preference ratios than did the control group (all ps $<.05$ ). The remaining groups did not differ reliably from the control group (all ps $>.05$ ). The groups differed reliably over the 60 -min test session $[F(6,48)=4.49, \mathrm{p}<.01]$. Scheffé multiple comparisons showed that the groups that were injected $0,15,30$, or $45 \mathrm{~min}$ after saccharin removal had lower saccharin preference ratios than the control group (all ps $<.01$ ). The remaining groups did not (all ps $>.05$ ).

The short taste-sickness delay contrasts with the delays of 8 and $12 \mathrm{~h}$ that have been obtained with adult rats (Nachman, 1970). One cannot argue that the young rats did not show an aversion because they could not withhold consumption. Apparently, conditions that are favorable to taste aversion learning in old rats are not appropriate for young rats.

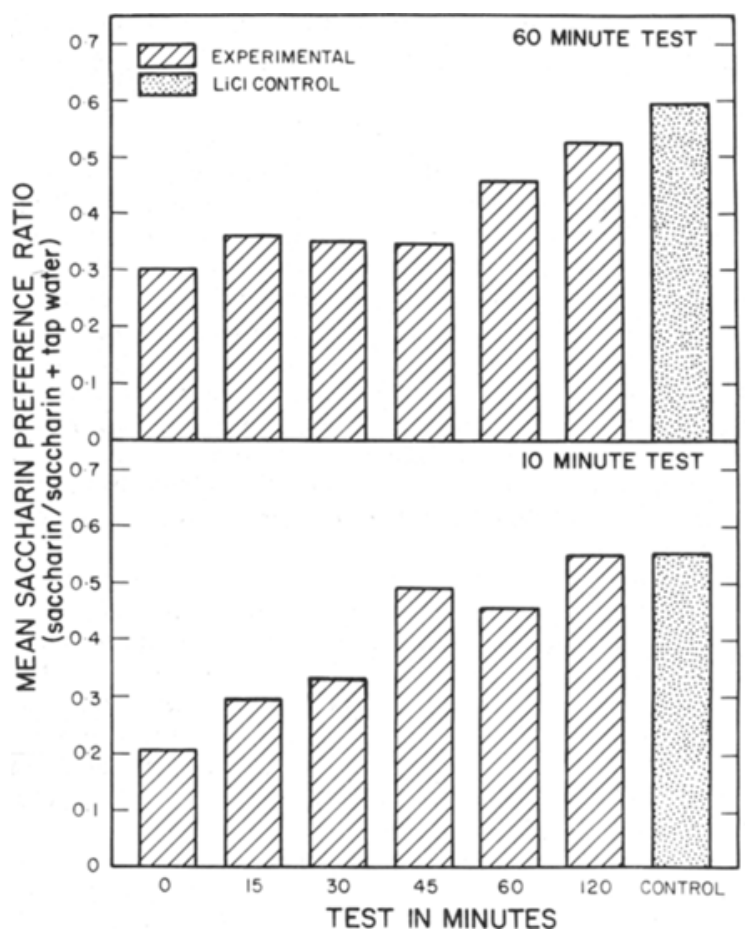

Figure 2. Mean saccharin preference ratios of groups that were injected with $\mathrm{LiCl}$ after saccharin consumption (EXPERIMENTAL) or lap water consumption (CONTROL) in Experiment 3.

\section{EXPERIMENT 4}

Findings from several experiments indicate that increases in the intensity of the flavor and sickness would help overcome the apparent weak aversions observed in our 23-day-old rats. A low dosage of $\mathrm{LiCl}$ that produces a weak aversion in adult rats (Nachman \& Ashe, 1973) does not produce an aversion in young rats (Franchina, Domato, \& McCleese, 1979). Fourteen-day-old rats form taste-sickness associations over a delay of $2 \mathrm{~h}$ when the concentration of saccharin is .5\% (Gregg et al., 1978), and they show better retention of a taste aversion with high, rather than low, flavor concentrations (Campbell \& Alberts, 1979).

We determined whether our rats formed stronger taste aversions under our training and test conditions when the concentration of saccharin was increased to $1.0 \%$ and the dosage of $\mathrm{LiCl}$ was increased to $.65 \mathrm{M}$. The strength of a saccharin aversion was measured in three ways: Experiment 4A examined the extinction of the aversion in rats that were trained when 23 days old and tested when 26 days old. Experiment $4 \mathrm{~B}$ examined the extinction of the aversion in rats that were trained when 23 days of age and tested when 72 days old, and Experiment $4 \mathrm{C}$ determined whether 23-day-old rats could form a 
taste-sickness association over a delay longer than the 45 min observed in Experiment 3.

\section{Method}

In all three experiments, the deprivation procedure was the same as that used in Experiment 1. Rats in the experimental and saline groups had $1.0 \%$ saccharin substituted for tap water during the 10 -min drinking session at $1000 \mathrm{~h}$ when they were 23 days old. After saccharin removal, the experimental group was injected with $.65 \mathrm{M} \mathrm{LiCl}$ at a dosage of $1 \mathrm{ml} / 100 \mathrm{~g}$ body weight, and the saline control group was injected with an equivalent volume of physiological saline. The $\mathrm{LiCl}$ control group was given tap water when 23 days of age and was injected with $\mathrm{LiCl}$ at a dosage equivalent to that given the experimental group. All animals were tested on $1.0 \%$ saccharin during the 1000 -h drinking session. Measures of fluid consumption were taken at the end of 10 and $60 \mathrm{~min}$.

Experiment 4A. The experimental, saline control, and $\mathrm{LiCl}$ control groups had 9,11 , and 12 rats, respectively. The rats were tested on $1.0 \%$ saccharin when 26,27 , and 28 days of age.

Experiment 4B. The experimental, the saline control, and $\mathrm{LiCl}$ control groups each contained eight rats. After training, the rats were moved to group cages. They were returned to individual cages and the deprivation procedure was reinstated when they were 72 days of age. The rats were tested on $1.0 \%$ saccharin when they were 75,76 , and 77 days of age.

Experiment $\mathbf{4 C}$. There were eight rats in the $\mathrm{LiCl}$ control group and 40 rats in the experimental group. The animals in the experimental group were divided equally among five groups and were injected with $\mathrm{LiCl} .5,1.0,1.5$, or $2.5 \mathrm{~h}$ after the saccharin was removed. All animals were tested on $1.0 \%$ saccharin when they were 26 and 27 days of age. One rat in the 1.5-h group died prior to testing.

\section{Results and Discussion}

The groups differed reliably on the training day in Experiments 4A $[\mathrm{F}(2,29)=5.72, \mathrm{p}<.025], 4 \mathrm{~B}$ $[\mathrm{F}(2,21)=29.11, \mathrm{p}<.01]$, and $4 \mathrm{C}[\mathrm{F}(5,41)=8.90$, $\mathrm{p}<.01]$. Scheffé multiple comparisons showed that the experimental groups' saccharin consumption in Experiments $4 \mathrm{~A}$ (mean $=2.2 \mathrm{ml}), 4 \mathrm{~B}($ mean $=2.4 \mathrm{ml}$ ), and $4 \mathrm{C}$ (means $=2.1,2.5,1.9,2.2$, and $1.7 \mathrm{ml}$ ) and the saline control groups' saccharin consumption in Experiments $4 \mathrm{~A}$ (mean $=2.1 \mathrm{ml}$ ) and $4 \mathrm{~B}$ (mean $=$ $2.3 \mathrm{ml}$ ) were reliably less (all ps $<.05$ ) than the tap water consumption of the $\mathrm{LiCl}$ control groups in Experiments $4 \mathrm{~A}($ mean $=3.5 \mathrm{ml}), 4 \mathrm{~B}($ mean $=4.2 \mathrm{ml})$, and $4 \mathrm{C}$ (mean $=4.9 \mathrm{ml}$ ). Furthermore, correlated $t$ tests revealed that the control groups' saccharin consumption increased reliably (all ps $<.05$ ) between the first and the second test in Experiments 4A (mean $=4.8$ to $7.9 \mathrm{ml}$ and mean $=4.3$ to $7.2 \mathrm{ml}$, by the $\mathrm{LiCl}$ and saline control groups, respectively), $4 \mathrm{~B}$ (mean $=14.2$ to $18.0 \mathrm{ml}$ and mean $=14.0$ to $18.1 \mathrm{ml}$, by the $\mathrm{LiCl}$ and saline control groups, respectively), and $4 \mathrm{C}$ (mean $=4.3$ to $8.0 \mathrm{ml}$, by the $\mathrm{LiCl}$ control group). These observations indicate that the 23-day-old rats noticed the $1.0 \%$ saccharin and that their fear of it disappeared over repeated presentations. A similar observation has been made on adult, but not young, rats by several investigators (e.g., Domjan, 1977).
The aversions observed in Experiments 4A, 4B, and $4 \mathrm{C}$ were stronger than those observed to $.1 \%$ saccharin in the first three experiments. The groups differed reliably over $60 \mathrm{~min}$ in Experiment $4 \mathrm{~A}$ during Test $1[\mathrm{~F}(2,29)=4.03, \mathrm{p}<.05]$ and Test $2[\mathrm{~F}$ $(2,29)=6.19, \mathrm{p}<.01]$, but not Test $3[F(2,29)=$ $1.68, \mathrm{p}>.05]$. Scheffé multiple comparisons showed that the experimental group (means $=2.5$ and $4.9 \mathrm{ml}$ for Tests 1 and 2, respectively) dirank reliably less (all ps $<.05$ ) $1.0 \%$ saccharin than did the $\mathrm{LiCl}$ (means $=$ 4.8 and $8.0 \mathrm{ml}$ for Tests 1 and 2 , respectively) and the saline (means $=4.5$ and $7.5 \mathrm{ml}$ for Tests 1 and 2 , respectively) control groups. In Experiment 4B, the groups differed reliably over $60 \mathrm{~min}$ during Tests 1 $[F(2,21)=22.60, p<.01]$, Test $2[F(2,21)=11.55$, $\mathrm{p}<.01]$, and Test $3[\mathrm{~F}(2,21)=4.5, \mathrm{p}<.05]$. Scheffé multiple comparisons showed that the experimental group (means $=4.2,10.0$, and $15.6 \mathrm{ml}$ for Tests 1 , 2 , and 3 , respectively) drank reliably less $1.0 \%$ saccharin (all ps $<.05$ ) than did the $\mathrm{LiCl}$ (means $=14.2$, 18.0 , and $20.1 \mathrm{ml}$ for Tests 1,2 , and 3, respectively) and the saline (means $=14.0,18.1$, and $21.0 \mathrm{ml}$ for Tests 1, 2, and 3, respectively) control groups. In Experiment $4 C$, the groups differed reliably over 60 min during Test $1[F(5,41)=4.30, p<.01]$ and Test $2[F(5,41)=4.12, p<.01]$. Scheffé multiple comparisons revealed that all experimental groups drank reliably less (all ps $<.01$ ) $1.0 \%$ saccharin than did the $\mathrm{LiCl}$ control group during Test 1 and that all groups, with the exception of the 2.5 -h group, drank reliably (all ps $<.05$ ) less than the $\mathrm{LiCl}$ control group during Test 2 (see Figure 3 for a summary of the means).

One other difference between the findings of these experiments and the first three experiments was the absence of any differences between the groups during the first $10 \mathrm{~min}$ of Test 1 in Experiments 4A $[F(2,29)=1.76, p>.05]$ and $4 C[F(5,41)=1.63$, $\mathrm{p}>$.05]. Apparently, group differences were masked by the absence of drinking during the first $10 \mathrm{~min}$ of the initial test.

\section{GENERAL DISCUSSION}

Our findings indicate that any attempt to draw conclusions about the ability of young rats to form a taste-sickness association is fraught with difficulties. The performance of young rats varied as a function of manipulations in stimulus parameters and test procedures. The importance of these manipulations indicates that any experiment that fails to obtain learned aversions in young rats may have selected the wrong parameters. Furthermore, the manipulations required to demonstrate learned aversions in young rats may reflect differences between them and old rats in associative ability or in sensitivity 


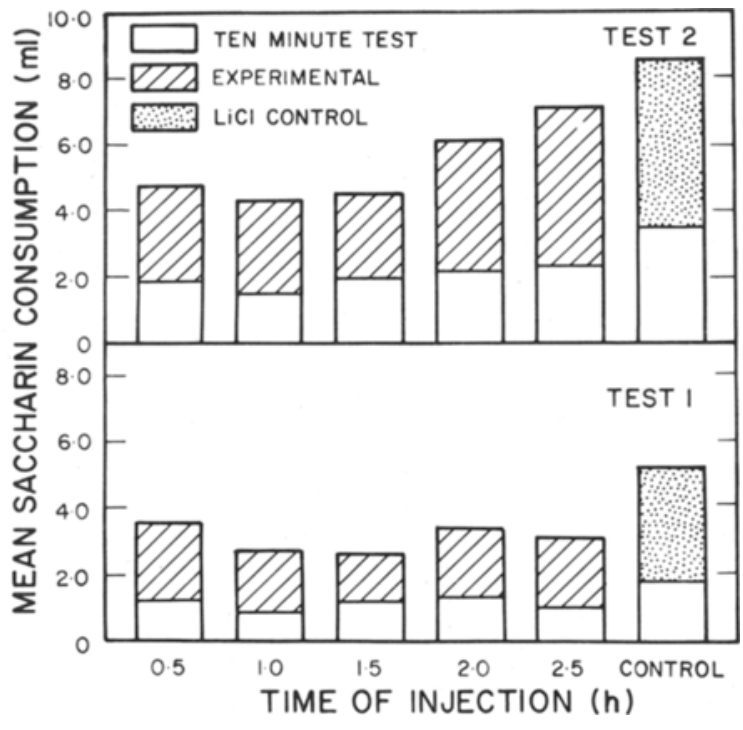

Figure 3. Mean amounts of saccharin consumed on the 2 test days by the groups in Experiment $\mathbf{4 C}$. The lower white portion represents the fluid consumed in the first $\mathbf{1 0} \mathbf{~ m i n}$.

to stimulus parameters and deprivation procedures employed.

Klein et al. (1975) showed that a choice test was required to demonstrate an aversion in young rats. We confirmed this and showed that young rats still formed weaker aversions than did old rats when this difficulty was taken into account and the delay between the taste and sickness was increased. The latter finding was consistent with the observation that young rats form taste-sickness associations over short, but not long, delays (Baker et al., 1977). This was not the case, however, when the concentrations of saccharin and $\mathrm{LiCl}$ were increased. Hence, our findings agreed with those of Gregg et al. (1978), who reported that 15-day-old rats form taste-sickness associations over a delay of $2 \mathrm{~h}$. They did not obtain taste-sickness associations over a delay greater than $30 \mathrm{~min}$ when the rats were 12 days old. Such a fail- ure, in the light of our findings, could reflect either an inability of 12-day-old rats to form such associations or inappropriate stimulus parameters. Similarly, Campbell and Alberts (1979) found that 10and 12-day-old rats showed retention deficits when tested 5 or 10 days later. Such deficits could reflect problems with retention or differences in sensitivity to the stimuli involved. Furthermore, our findings indicate that manipulations in stimulus intensity alone are not adequate to ensure an accurate assessment of the ability of young rats to form taste-sickness associations. For example, we found an aversion to $.1 \%$ saccharin was revealed with a $10-\mathrm{min}$, but not a 60 -min, test. The reverse was true when $1.0 \%$ saccharin was employed.

\section{REFERENCES}

Baker, L. J., Baker, T. B., \& Kesner, R. P. Taste aversion learning in young and adult rats. Journal of Comparative and Physiological Psychology, 1977, 91, 1168-1178.

Campbell, B. A., \& Alberts, J. R. Ontogeny of long-term memory for learned taste aversions. Behavioral and Neural Biology, 1979, 25, 138-156.

Domsan, M. Attenuation and enhancement of neophobia for edible substances. In L. M. Barker, M. R. Best, \& M. Domjan (Eds.), Learning mechanisms in food selection. Waco, Tex: Baylor University Press, 1977.

Franchina, J. J., Domato, G. C., \& McClesse, D. Learning and retention of sucrose taste aversion in weanling rats. Bulletin of the Psychonomic Society, 1979, 14, 91-94.

Gregg, B., Kittrell, E. M. W., Domjan, M., \& Amsel, A. Ingestional aversion learning in preweanling rats. Journal of Comparative and Physiological Psychology, 1978, 92, 785-795.

Klein, S. B., Domato, G. G., Hallstead, C., Ste Phens, I., \& Mikulka, P. J. Acquisition of a conditioned aversion as a function of age and measurement technique. Physiological Psychology, 1975, 3, 379-384.

Nachman, M. Learned taste and temperature aversions due to lithium chloride sickness after temporal delays. Journal of Comparative and Physiological Psychology, 1970, 73, 22-30.

Nachman, M., \& Ashe, J. H. Learned taste aversions in rats as a function of dosage, concentration, and route of administration of LiCl. Physiology \& Behavior, 1973, 10, 73-78.

(Received for publication March 4, 1980; revision accepted July 29,1980 .) 